\title{
Brushless DC Motor Speed Control using PID Controller, Fuzzy Controller, and Neuro Fuzzy Controller
}

\author{
Ahmed K. Hassan \\ MSc Student at \\ Computers and Systems \\ Engineering Department, \\ Faculty of Engineering \\ Mansoura University, \\ Egypt
}

\author{
Mohammed S. \\ Saraya \\ Lecturer at Computers \\ and Systems Engineering \\ Department, \\ Faculty of Engineering \\ Mansoura University, \\ Egypt
}

\author{
Mohamed S. Elksasy \\ Assist. Prof at Computers \\ and Systems Engineering \\ Department, \\ Faculty of Engineering \\ Mansoura University, \\ Egypt
}

\author{
Fayez F. Areed \\ Prof at Computers and \\ Systems Engineering \\ Department \\ Faculty of Engineering \\ Mansoura University, \\ Egypt
}

\begin{abstract}
Brushless dc motors (BLDC motors) are commonly used nowadays in industry and at many applications according to its very high speed with a very compact size in comparison to the older motors with brushes, moreover the importance of being powered by direct current (DC) and without all disadvantages of using brushes, which is convenient to many applications like hard drivers, CD/DVD players, electric bicycles, electric and hybrid vehicles, CNC machines and Aero modeling. The purpose of this paper is to control the speed of a brushless dc motor by using PID controller, Fuzzy logic controller, and Neuro fuzzy controller. According to these varieties of control techniques which used to control the speed, we have many parameters which used to assess that which controller will be better to use.
\end{abstract}

\section{Keywords}

BLDC Motor, Speed Control, PID Controller, Fuzzy Controller, Neuro fuzzy controller,ANFIS.

\section{INTRODUCTION}

BLDC motors according to the long operating life, operating without any noise, the very high speed range, the very high efficiency, dynamically faster response are now widely used in many applications, such as servo drives, computer DVD burners, and electrical vehicles. Moreover, the lack of brushes usage in BLDC motor gives us some advantages such as [1]:

- $\quad$ BLDC motor has no noise.

- There is no sparks, which means it will be suitable for any hazardous work environment and any sensitive media.

- The compacted size for the motor.

- No need to change the brushes, which leads to low cost of maintenance.

- The torque and acceleration have better performance.

A brushless DC motor is a synchronous electrically powered motor which is powered by DC electrical current and it is different than dc motor because of its electronically commutation control, instead of the old way of a mechanical commutation system which uses brushes.

It's well known for us that PID controller still a very reliable control technique according to many characteristics as, the very satisfying performance with the tuning methods with any linear system, low Cost, dealing with it is simpler than other techniques and very limited maintenance. According to all of the pervious characteristics
PID still very preferred in industry and at many automatic control applications, and it also used with BLDC motor, but the problem which rises with PID technique are the non-linear systems, the problem of affecting the speed after adding any additional loads, suffering from changing dynamics after a long time operation which will be very difficult to be covered with a fixed PID controller. Moreover, the external noise which make PID controller not be the perfect choice to control the BLDC motor in these circumstances because it means that we need to change the parameters dynamically. All of these reasons leading us to think about a more flexible and suitable controller like fuzzy logic controller which depends on the linguistic rules that make the system more flexible and more dynamic.

And if we need to talk about a more dynamic controller shifting us from a flexible controller to a new zone of an intelligent controller we will talk about using ANFIS (Adaptive Neuro Fuzzy Inference Systems) controller which makes our system dynamic because of using training, learning and testing techniques which make an enhancement in the performance [3].

\section{PID CONTROLLER}

At any process, we need to use a control technique to design convenient controller to overcome any error, minimize the error and to reach the desired target at minimum time. In the case of speed control we can define error of speed equation as:

$e(t)=\omega \mathrm{d}(\mathrm{t})-\omega \mathrm{a}(\mathrm{t})$

$u(t)=k_{P} e(t)+k_{I} \int_{0}^{t} e(t) d t+k_{D} \frac{d e(t)}{d t}$

Where:

$u(t)$ is the output signal from the controller.

$k_{p} \quad$ is the proportional gain of the controller.

$k_{I}$ is the integral gain of the controller.

$\mathrm{k}_{\mathrm{D}}$ is the derivative gain of the controller.

$e(t)$ is the error function.

The following block diagram, in figure 1 explains the operation of our PID controller. 


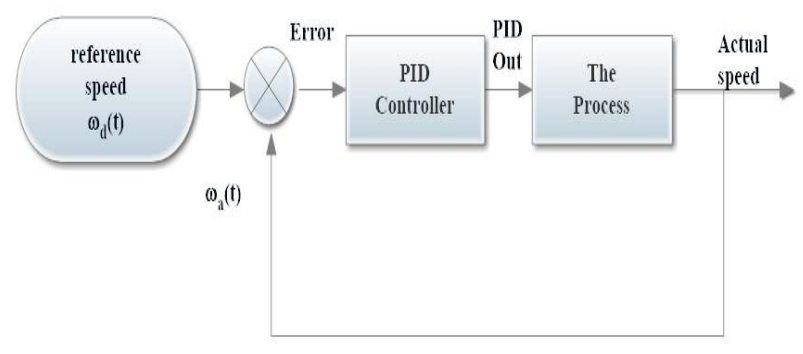

Figure 1 PID Controller Block Diagram

\section{FUZZY CONTROLLER}

Fuzzy Controller is a logical, linguistic controller depends on linguistic rules which make the connection between inputs and outputs. The biggest motivation to use fuzzy control system is to describe complicated real world problem into a model but in a linguistic form depends on rules (IF-Then statement), All of that means that this technique of control has a very amazing advantage which it will be effortless to understand and to implement like categorizing speed as low, moderate and fast[2].

The fuzzy controller has mainly four components according to:

- Fuzzification : its defined as the process of converting the input analog signals to values can be compared with rules in rule base.

- The inference mechanism: it's defined as the mechanism which decides the control rules related at the current time and then make the convenient input to the system.

- $\quad$ Rule base: it's defined as the linguistic logical rules using (IF-THEN) conditions to get the desired output.

- Defuzzification : its defined as the process of converting the result of applying rules from fuzzy logical form into analog form to be entered to the plant.

The following block diagram, in figure 1 explains the operation of our Fuzzy controller.

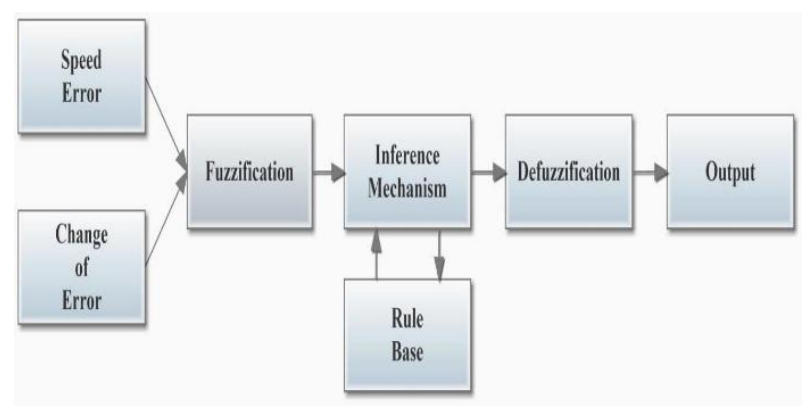

Figure 2 Fuzzy Controller block diagram

\section{NEURO-FUZZY CONTROLLER}

The ANFIS technique (Adaptive Neuro Fuzzy Inference system) simply constructs an input output network depends on feed forward learning techniques; its construction consists of nodes and links connecting these nodes which all of them are adaptive targeting to minimize error as possible by learning[5],[8]

The ANFIS design briefly consists of two parts: constructing

And training. In the constructing part, structure factors are Considered. We have type and number of input membership functions (MFs), and type of output membership function(MF).

Hence, ANFIS depends on neural networks techniques for learning so we are taking about feed forward, back propagation and hybrid systems like making mix between back propagation and least square error[3],[4].

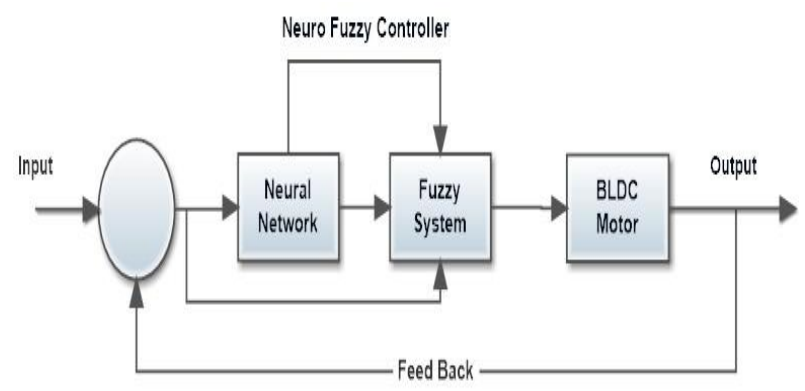

Figure 3 Neuro Fuzzy Controller block diagram

\section{PID CONTROLLER SIMULATION RESULTS}

Most of industrial applications use PID Controller because of its ease of usage and the simplicity of tuning parameters at the site but we noticed that derivative part sometimes with relative bigger value make the system unstable. The used coefficients for our Controller after many trials with try and error method and Ziegler Nichols method are $\mathrm{KP}=0.15, \mathrm{KI}=20$, and $\mathrm{KD}=0.0001$.

At the start, the speed was zero, and at $0.066 \mathrm{sec}$ the speed increased to 800 RPM, at $0.089 \mathrm{sec}$ the speed increased to 1000 rpm at $0.1 \mathrm{sec}$ a load of

$10 \%$ is added which makes undershoot at speed $2.1 \%$ the speed comes back to its value $1000 \mathrm{rpm}$ after $0.015 \mathrm{sec}$.

Figure 4 shows the used simulation model in Simulink for the PID speed controller. 


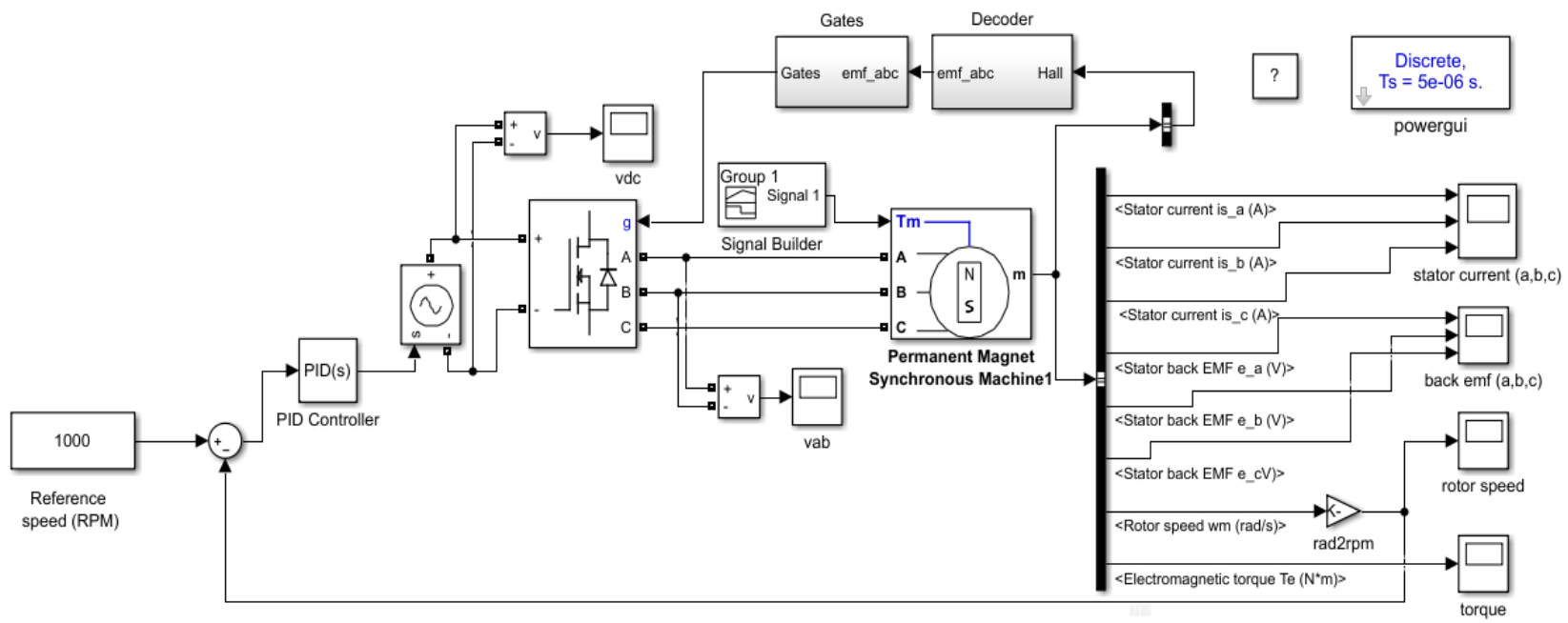

Figure 4 Used Simulink model for PID Controller

In figure 5 , we can see the response of the motor to the controller the rise time is $0.00482 \mathrm{sec}$, the settling time is $0.0215 \mathrm{sec}$. and we have an overshooting $2.05 \%$.

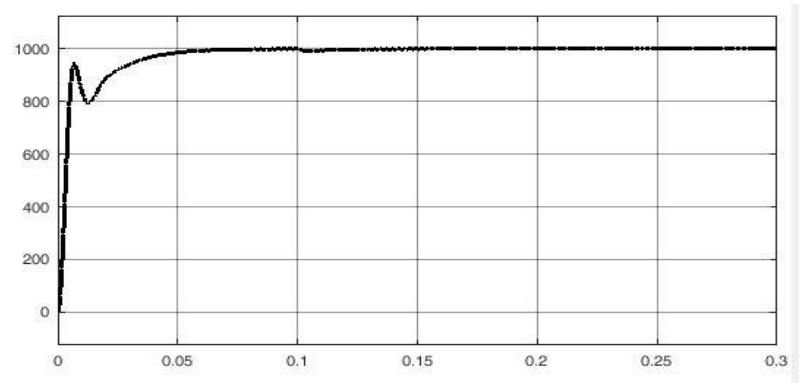

Figure 5 speed response for PID Controller

In figure 6 , the torque has a startup value with about 6.6 N.m and reached steady state at $0.025 \mathrm{sec}$., and increased again at time $0.1 \mathrm{sec}$. According to the increased load. The torque ripples are about $3.71 \%$.

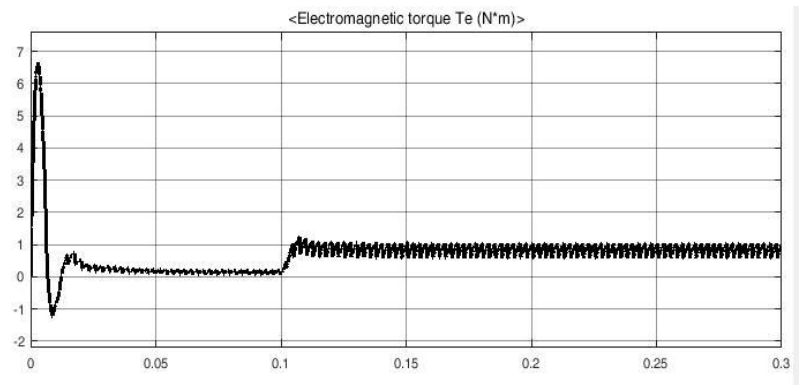

Figure 6 torque response for PID Controller

\section{FUZZY SIMULATION RESULTS}

At the start, the speed was zero, and at $0.0132 \mathrm{sec}$ the speed increased to $800 \mathrm{RPM}$, at $0.0165 \mathrm{sec}$ the speed increased to $1000 \mathrm{rpm}$ at $0.1 \mathrm{sec}$ a load of

$10 \%$ is added which makes undershoot at speed $0.72 \%$ the speed comes back to its value $1000 \mathrm{rpm}$ after $0.0104 \mathrm{sec}$.

As we say before we can use fuzzy logic controller to improve the performance of the system, and in figure 7, we can see the response of the motor to the controller the rise time is 0.00977 sec., the settling time is 0.0104 sec. and we have an overshooting $1.53 \%$

In figure 8 , the torque has a startup value with about 3.1 N.m and reached steady state at $0.022 \mathrm{sec}$. and increased again at time 0.1 according to the increased load. The torque ripples are about $2.48 \%$.

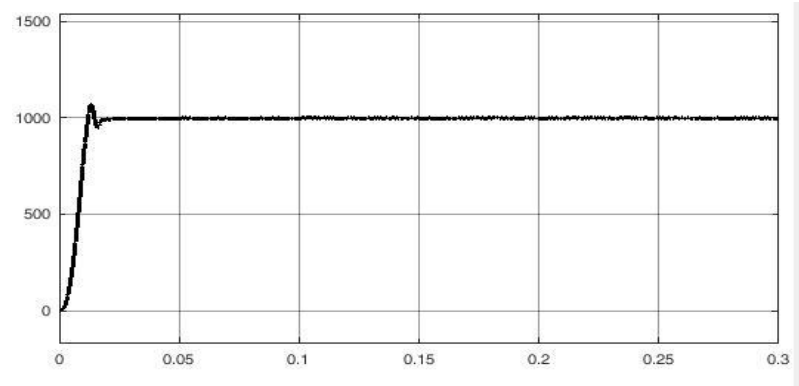

Figure 7 Speed Response for Fuzzy Controller

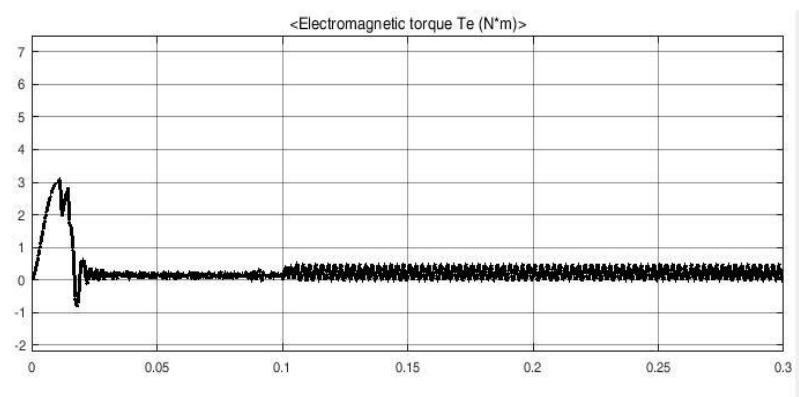

Figure 8 torque response for Fuzzy Controller

As shown in Figure 9 at model we have gains multiplied by error and change of error to easily optimizing the Fuzzy Controller and can simply change the range of the membership function; we have a gain 0.1 for the error and 0.17 for the change of error. 


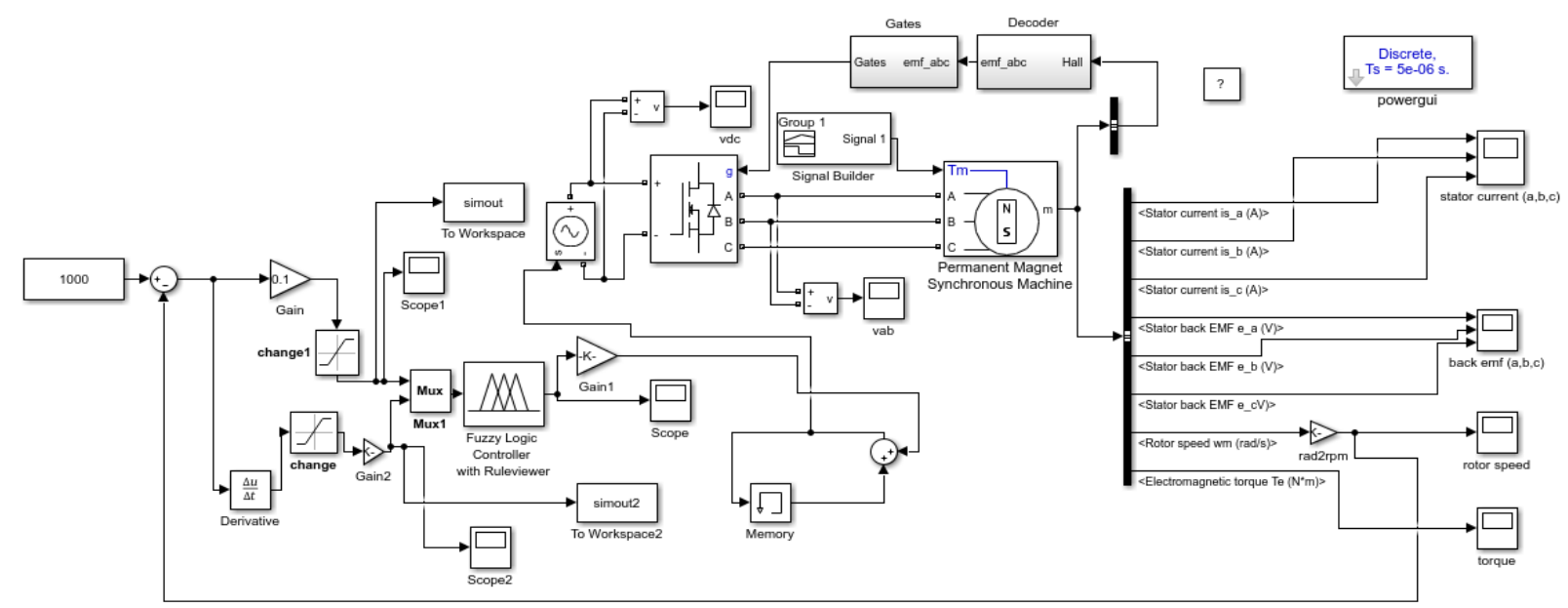

Figure 9 Used Simulink model for Fuzzy Controller

Our fuzzy controller uses 5 fuzzy sets, NB, N, ZERO, P, and PB. And with two inputs, the first one is the error and the second is the change of error, and we also have membership functions as shown in figure 10:

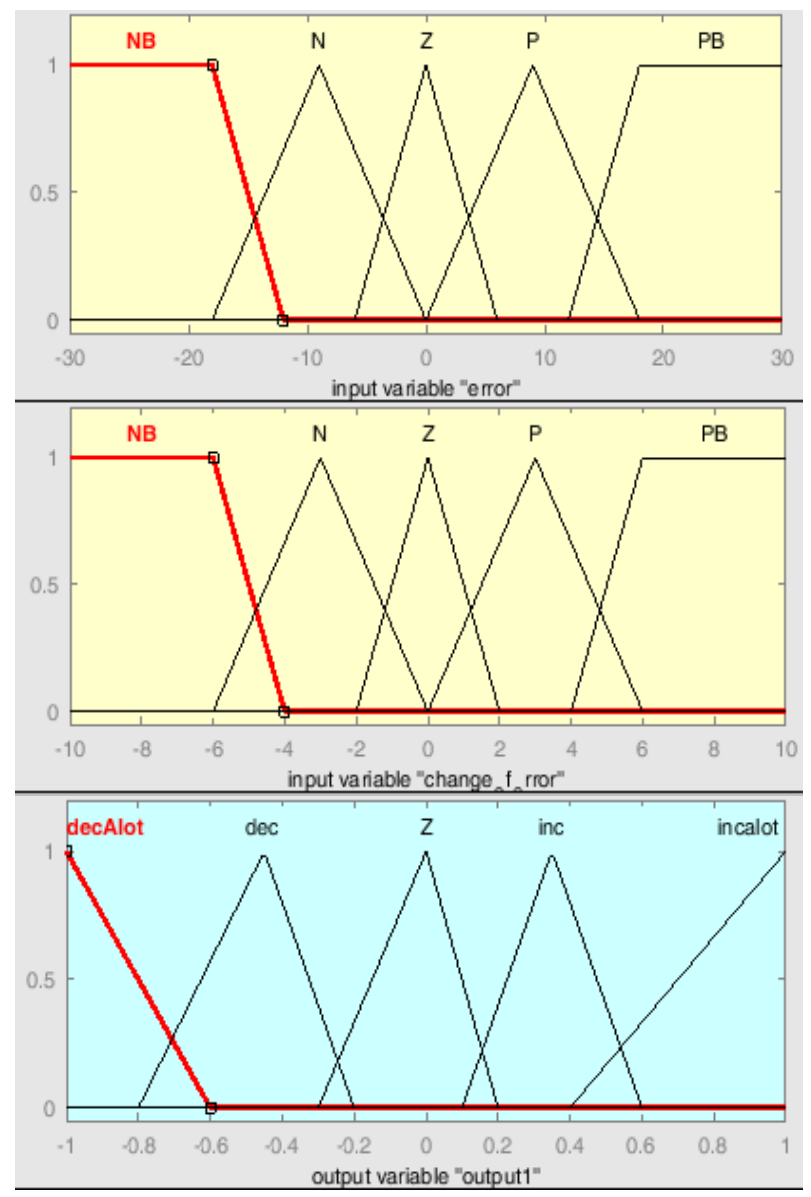

Figure 10 Fuzzy Membership Function

\section{FUZZY CONTROLLER RULE BASE}

Table 1 shows the rule base of the fuzzy controller used; there are 25 rule used from the 5 fuzzy sets of the two inputs.
Table 1 Fuzzy Controller Rule Base

\begin{tabular}{|l|l|l|l|l|l|}
\hline \multicolumn{1}{|c|}{ C E } & NB & $\mathrm{N}$ & ZERO & $\mathrm{P}$ & $\mathrm{PB}$ \\
\hline $\mathrm{NB}$ & BIGDEC & BIGDEC & BIGDEC & DEC & ZERO \\
\hline $\mathrm{N}$ & BIGDEC & BIGDEC & DEC & ZERO & INC \\
\hline ZERO & BIGDEC & DEC & ZERO & INC & BIGINC \\
\hline $\mathrm{P}$ & DEC & ZERO & INC & BIGINC & BIGINC \\
\hline PB & ZERO & INC & BIGINC & BIGINC & BIGINC \\
\hline
\end{tabular}

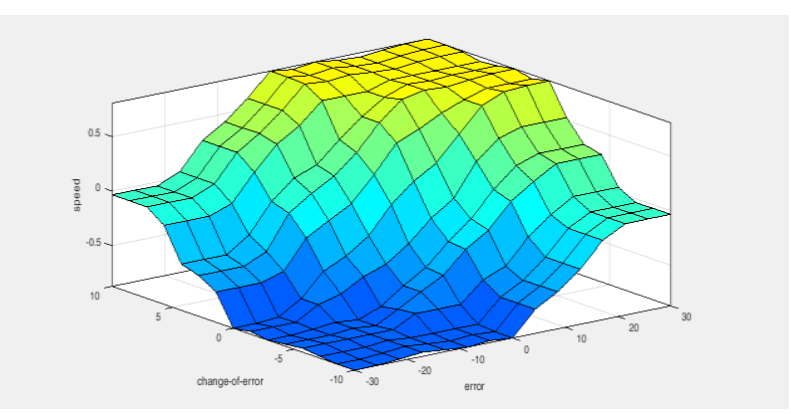

Figure 11 Fuzzy Surface of The Controller

\section{NEURO-FUZZY SIMULATION RESULTS}

As usual at any industry application we need all the time more effective performance with the fastest response, so it was the start of using some intelligent techniques depends on learning like Neuro Fuzzy techniques specially ANFIS (Adaptive Neuro Fuzzy Inference system) which also depends on Fuzzy logic controller and integrating these rules of fuzzy in neural network to make it learning in the system and to improve its performance very fast.

At the start, the speed was zero, and at $0.0119 \mathrm{sec}$ the speed increased to $800 \mathrm{RPM}$, at $0.0138 \mathrm{sec}$ the speed increased to $1000 \mathrm{rpm}$ at $0.1 \mathrm{sec}$ a load of

$10 \%$ is added which makes undershoot at speed $0.48 \%$ the speed comes back to its value $1000 \mathrm{rpm}$ after $0.00912 \mathrm{sec}$ 
In figure12, we can see the response of the motor to the controller the rise time is $0.00874 \mathrm{sec}$, the settling time is $0.0092 \mathrm{sec}$, and we have an overshooting $1.41 \%$.

In figure13, the torque has a startup value with about 1.9 N.m and reached steady state at $0.0213 \mathrm{sec}$., and increased again at time 0.1 according to the increased load. The torque ripples are about $2.29 \%$.

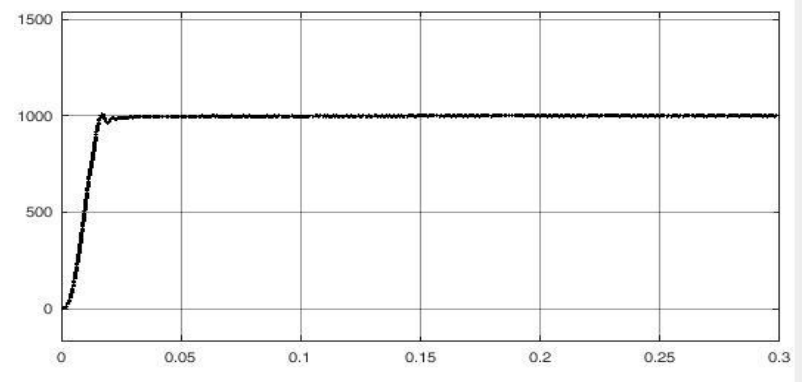

Figure 12 speed response for Neuro Fuzzy Controller

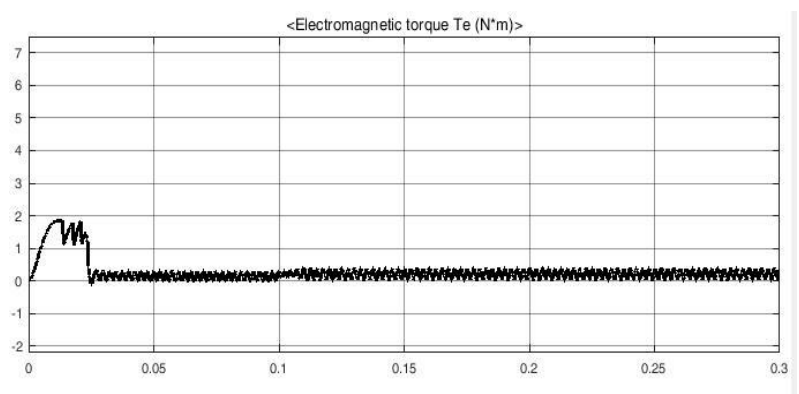

Figure 13 torque response for Neuro Fuzzy Controller

The structure consists of five layers. First layer is the input layer; second layer is the input membership function layer. Third layer is the rule layer where the inputs and outputs are linked. Fourth layer is the output membership function layer. Last layer is the output layer which sums up all the inputs coming from the previous layer; we can see the ANFIS (Adaptive Neuro Fuzzy Inference system) architecture in figure 14 [7]:

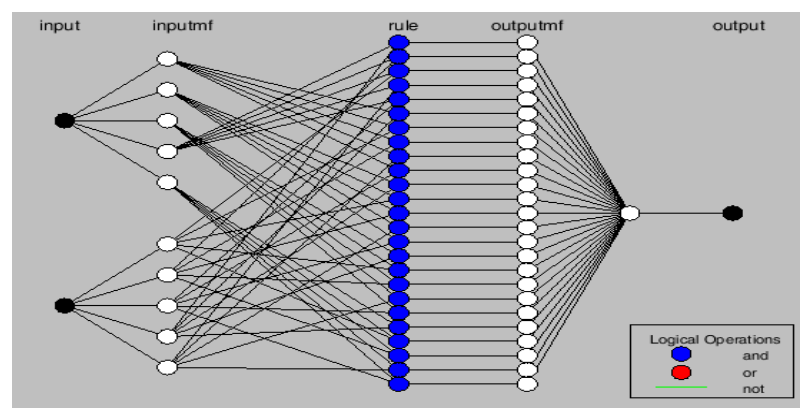

Figure 14 The ANFIS Controller Architecture

\section{PID CONTROLLER, FUZZY \\ CONTROLLER, AND NEURO FUZZY \\ CONTROLLER PERFORMANCE COMPARISON}

Table 2 has a comparison between all of our applied control techniques:

Comparative study:
Table 2 Comparative study

\begin{tabular}{|l|l|l|l|}
\hline \multicolumn{4}{|l|}{ Reference: } \\
\hline Speed & Rise Time & Settling time & Torque ripples \\
\hline PID & 0.005 & 0.025 & $5.43 \%$ \\
\hline Fuzzy & 0.02 & 0.023 & $4.82 \%$ \\
\hline Our Controller : & Rise Time & Settling time & Torque ripples \\
\hline Speed & 0.00482 & 0.0215 & $3.71 \%$ \\
\hline PID & 0.00977 & 0.0104 & $2.48 \%$ \\
\hline Fuzzy & 0.00874 & 0.0092 & $2.29 \%$ \\
\hline $\begin{array}{l}\text { Neuro } \\
\text { Fuzzy }\end{array}$ & & & \\
\hline
\end{tabular}

\section{CONCLUSION AND FUTURE WORK}

PID controller has a moderate response with $10 \%$ load from rated torque.it has a very good rise time $0.00482 \mathrm{sec}$. and settling time $0.0215 \mathrm{sec}$, with startup torque 6.6 N.M and torque $\quad$ ripples $3.71 \%$. Fuzzy controller has a good response with the same $10 \%$ load from rated torque.it has a rise time $0.00977 \mathrm{sec}$. which is longer slightly than PID controller but the settling time is $0.0104 \mathrm{sec}$. which is better than PID controller, with a decreased startup torque 3.1 N.M and torque ripples has decreased to $2.48 \%$ so we can conclude that totally fuzzy controller performance is better than PID controller.

Neuro Fuzzy controller has a very good response with the same $10 \%$ load from rated torque. It has a rise time $0.00874 \mathrm{sec}$. which is better than Fuzzy controller and with settling time $0.0092 \mathrm{sec}$. which is slightly better than Fuzzy controller, with startup torque decreased to 1.9 N.M, and torque ripples has decreased slightly to $2.29 \%$ so we can conclude that Neuro Fuzzy controller is better than Fuzzy controller. Briefly speaking we can say that PID controller is a simple controller with a simple tuning method but with a moderate response and performance. Fuzzy controller is more complicated controller but with a good and more stable performance. Euro fuzzy controller is very complicated controller but with a very good performance.

A future work which may be very effective to use a combination between two control techniques like neuro fuzzy and genetic controller to enhance the performance of the controller and then the speed control of the motor and minimize torque ripples of the motor

\section{REFERENCES}

[1] Ahmed, A. M., Ali-Eldin, A., Elksasy, M. S., \& Areed, F. F. (2015). Brushless DC motor speed control using both PI controller and fuzzy PI controller. International Journal of Computer Applications, 109(10), 29-35.

[2] Mustafa, G. Y., Ali, A. T., Bashier, E., \& Elrahman, M. F. (2013). Neuro-fuzzy controller design for a dc motor drive. University Of Khartoum Engineering Journal, 3(1).

[3] Tiwari, N., RITEE, R. C., \& Diwan, R. Speed Control of Brushless DC Motor using Fuzzy and Neuro Fuzzy.

[4] Mosavi, M. R., Rahmati, A., Khoshsaadat, A., \& Elektrotechniczny, P. (2012). Design of efficient adaptive neuro-fuzzy controller based on supervisory learning capable for speed and torque control of BLDC motor. PRZEGLAD ELEKTROTECHNICZNY (Electrical Review), $R, 88$. 
[5] Yashoda, M., \& Sekhar, O. C. (2016). Design and Analysis of ANFIS based BLDC Motor. Indian Journal of Science and Technology, 9(35).

[6] Arulmozhiyal, R., \& Kandiban, R. (2012, July). An intelligent speed controller for Brushless DC motor. In Industrial Electronics and Applications (ICIEA), 2012 7th IEEE Conference on (pp. 16-21). IEEE.
[7] Navaneethakkannan, C., \& Sudha, M. (2016). Analysis and Implementation of ANFIS-based Rotor Position Controller for BLDC Motors. Journal of Power Electronics, 16(2), 564-571.

[8] Jang, J. S. (1993). ANFIS: adaptive-network-based fuzzy inference system. IEEE transactions on systems, man, and cybernetics, 23(3), 665-685. 